\title{
Insulin-like growth factor-1 genotypes and haplotypes influence the survival of prostate cancer patients with bone metastasis at initial diagnosis
}

\author{
Norihiko Tsuchiya', Shintaro Narita', Takamitsu Inoue1, Mitsuru Saito ${ }^{1}$, Kazuyuki Numakura', Mingguo Huang ${ }^{1}$, \\ Shingo Hatakeyama², Shigeru Satoh', Seiichi Saito ${ }^{3}$, Chikara Ohyama², Yoichi Arai ${ }^{4}$, Osamu Ogawa ${ }^{5}$ \\ and Tomonori Habuchi ${ }^{{ }^{*}}$
}

\begin{abstract}
Background: The insulin-like growth factor-1 (IGF-1) plays an important role in growth of prostate cancer (PCa) cells and facilitating the development and progression of PCa. This study aimed to evaluate the association of polymorphisms in three linkage disequilibrium (LD) blocks of the IGF-1 on the survival of metastatic PCa patients.

Methods: A total of 215 patients with bone metastases at initial presentation were included in this study. The cytosine-adenine (CA) repeat polymorphism and rs12423791 were selected as representative polymorphisms in the LD blocks 1 and 2, respectively. Haplotype in the LD block 3 was analyzed using two tag single nucleotide polymorphisms (SNPs), rs6220 and rs7136446. Cancer-specific survival rate was estimated from the Kaplan-Meier curve, and the survival data were compared using the log-rank test.

Results: Cancer-specific survival was significantly associated with the CA repeat polymorphism, rs12423791, and rs6220 ( $P=0.013,0.014$, and 0.014 , respectively). Although rs7136446 had no significant association with survival, the haplotype in the LD block 3 was significantly associated with cancer-specific survival $(P=0.0003)$. When the sum of the risk genetic factors in each LD block (19-repeat allele, C allele of rs12423791, or C-T haplotype) was considered, patients with all the risk factors had significantly shorter cancer specific-survival than those with 0-2 risk factors $(P=0.0003)$.
\end{abstract}

Conclusions: Polymorphisms in the IGF-1, especially a haplotype in the LD block 3, are assumed to be genetic markers predicting the outcome of metastatic PCa.

Keywords: Prostate cancer, Bone metastasis, Survival, Polymorphism, Insulin-like growth factor-1

\section{Background}

Prostate cancer is typically a type of slow-growing cancer and generally well controlled by endocrine therapies even if distant metastases are present. However, those patients with distant metastases exhibit disease progression within 12 to 18 months on average and gradually manifest resistant to endocrine therapies thereafter [1]. Because several new promising agents are available or

\footnotetext{
*Correspondence: thabuchi@doc.med.akita-u.ac.jp

'Department of Urology, Akita University Graduate School of Medicine, 1-1-1 Hondo, Akita 010-8543, Japan

Full list of author information is available at the end of the article
}

being tested for treatment of castration-resistant prostate cancer [2-4], it has been of importance to identify pretreatment prognostic factors in metastatic prostate cancer for adjusting treatment intensity in each patient. Clinical and laboratory factors such as extent of disease (EOD) score [5], serum alkaline phosphate (ALP) [6], hemoglobin (HGB) [7], and prostate specific antigen (PSA) [8] have been used as prognostic markers for those patients since 20 years ago. Recent studies suggest that patients' intrinsic genetic factors or an interaction with environmental factors may have an impact on progression or survival in advanced prostate cancer patients

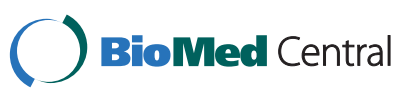


$[9,10]$. Our previous study demonstrated that the insulin-like growth factor-1 (IGF-1) and the cytochrome P450 aromatase (CYP19) polymorphisms were significantly associated with the cancer -specific survival of metastatic prostate cancer [10]. However, to date, investigations of genetic polymorphisms associated with cancer progression or survival have just begun and only a few reports are available in regard to a prostate cancer [11,12]. Evaluating outcomes using genetic makers combined with conventional prognostic markers is expected to lead to more accurate prediction of response to treatments or survival.

IGF-1 is involved in embryonic growth, homeostasis, and various diseases by regulating cell differentiation, proliferation, migration, and apoptosis. In the prostate, it plays an important role in the growth of both normal and cancer cells and facilitates the development and progression of prostate cancer $[13,14]$. Recent meta-analysis revealed that men with higher circulating IGF-1 levels had an increased risk of prostate cancer compared with men with lower IGF-1 levels [15] and the levels of circulating IGF-1 had a heritable component [16]. The same positive association was observed between circulating IGF-1 level and a risk for breast and colorectal cancer [17-21]. Meanwhile, a cytosine-adenine (CA) repeat polymorphism has been known to be located in the promoter region of the IGF-1 gene [22] and many studies investigated the influence of the polymorphism on the circulating IGF-1 level and risk for certain types of cancer [23]. Recent genome research revealed a number of single nucleotide polymorphism (SNP) throughout the IGF-1 region and haplotype analyses demonstrated that those SNPs were divided into three to four blocks in which SNPs for each block are in linkage disequilibrium (LD) each other $[24,25]$. Especially a haplotype in the LD block 3 located in a downstream of the $C A$ repeat has been suggested as a novel genetic variation associated with circulating IGF-1 level or cancer risk [25,26].

In this retrospective study, we aimed to evaluate the association of four polymorphisms in three LD blocks of the IGF-1 on the survival of prostate cancer patients with bone metastasis at initial diagnosis.

\section{Methods}

\section{Patients}

From July 1980 to September 2008, 215 native Japanese patients of prostate cancer with bone metastasis at initial presentation in Akita University Hospital and its related community hospitals, Kyoto University and Tohoku University Hospitals were enrolled in this study. Pathological diagnosis was made by prostate needle biopsy specimens and metastasis was identified by X-rays, CT scans, or bone scintigraphy. All the patients had no previous treatments at presentation and underwent surgical castration or luteinizing hormone-releasing hormone (LH$\mathrm{RH})$ analogues with or without antiandrogens as primary endocrine therapy. When the treatment failure was observed, optional therapies, including other antiandrogens, estrogens, steroids, chemotherapeutic agents, palliative radiation, or a combination of these was added or replaced.

Pathological grading of needle biopsy specimens was performed according to Gleason grading system by local pathologists with no designated primary pathologist. In 10 patients, the final pathological grade was not determined because no grade information was described in the final report or a different grading system was applied by the local pathologists. Pretreatment HGB, ALP, lactate dehydrogenase (LDH), and PSA levels before the initial treatment of prostate cancer were obtained from medical charts. An independent end-point reviewer in each institution determined the cause of death on the basis of standardized extractions from the patients' medical files without providing genotype data of each patient.

Written informed consent was obtained from all the patients enrolled in this study for the use of their DNA and clinical information. This study was approved by the Institutional Review Board (the Ethical Committee) in each institution.

\section{Genotyping analysis}

DNA was extracted from a peripheral blood sample of each patient using a QIAamp Blood Kit (QIAGEN, Hilden, Germany) or standard phenol-chloroform. We divided the IGF-1 gene into three LD blocks according to a previous report by Johansson et al. (Figure 1) [25]. The representative polymorphisms in each LD block were chosen with reference to literatures as the genes previously described to be associated with the circulating IGF1 level or the increased risk of prostate cancer [27] and SNP database of international HapMap project (http:// hapmap.ncbi.nlm.nih.gov/) [28]. The $C A$ repeat polymorphism in the promoter region and rs12423791 [GenBank] were selected from representative polymorphisms in the LD block 1 and 2, respectively. rs6220 [GenBank] and rs7136446 [GenBank] were selected as tag

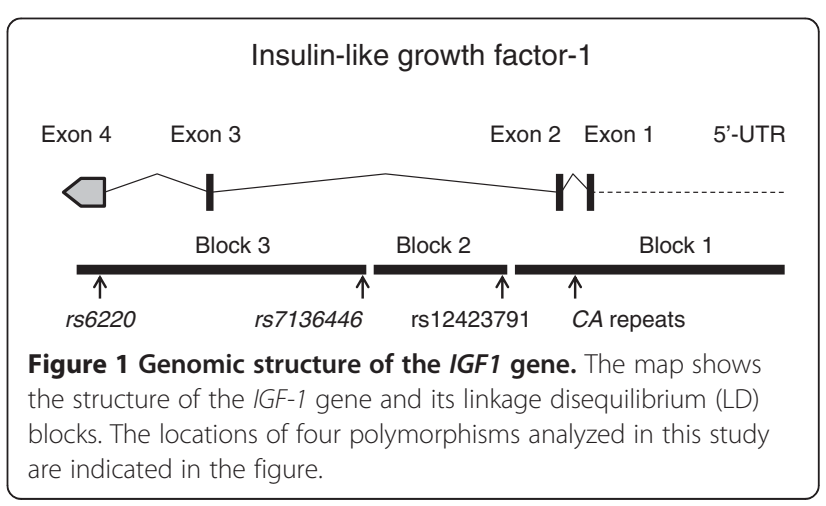


SNPs for a haplotype analysis in the LD block3. Genotypes of the $C A$ repeat polymorphism were determined by an automated sequencer (ABI PRISM 310 Genetic Analyzer) with GENESCAN software (Applied Biosystems, Foster City, CA) as described previously [17]. Other three SNPs were genotyped using polymerase chain reaction (PCR)restriction fragment length polymorphism (RFLP) method. The sequence of forward and reverse primers used for genotyping of the SNPs were as follows; $5^{\prime}$-GCTGC TTCTTCCAATGAGAG- ${ }^{\prime}$ and $5^{\prime}$-GAAAAGCATGTTGC TGCCTC-3' for rs12423791 (123 bp), and TGCCTAG AAAAGAAGGAATC- $3^{\prime}$ and $5^{\prime}$-TGACTCTTCTATGCAG TTAC-3' for rs6220 (105 bp), and 5'-CTTCTTGCAGAAC TAAGCTCAAGTC-3' and 5'-GCCTATTCATTTTCA CATACTACCC-3' for rs7136446 (126 bp). Each PCR product was digested with DdeI, MspI, and MnlI, respectively, overnight at $37^{\circ} \mathrm{C}$, and electrophoresed on $3.0 \%$ agarose gels to determine the genotype. Several samples were directly sequenced using Dye Terminator Sequencing Kit version 1.0 (PE Applied Biosystems) on an ABI prism 310 auto-sequencer to confirm the results of PCR-RFLP for each polymorphism.

\section{Statistical analysis}

The endpoint of this study was prostate cancer-specific survival. The survival time was calculated from the date of prostate cancer diagnosis to the date of death or the last contact with patients. To compare the survival, patients were dichotomized by the median value of age and PSA, by normal limits in HGB, ALP, LDH, by the tumor grade system (Gleason score). Haplotypes of the LD block 3 defined two SNPs, rs6220 and rs7136446, were inferred using expectation-maximization algorithm in SNPAlyze software ver.7 (Dynacom Co. Ltd., Chiba, Japan). Differences in survival between groups were analyzed using the logrank test. For the $C A$ repeat polymorphism, the number of repeats was dichotomized as having or not having the 19-repeat allele. Each SNP or haplotype was evaluated using dominant, recessive, and addictive model, and the most statistically significant model was selected. The IGF-1 polymorphisms and clinicopathological prognostic factors were assessed by the Cox proportional hazard regression models. Age, Gleason score, PSA, HGB, ALP, LDH, and the LD block 3 haplotype were employed as a variable set in a fullvariable model of multivariate analysis. Of the variables, Gleason score, HGB, ALP, and the LD block 3 haplotype were selected in a reduced variable model. Cancerspecific survival was estimated using the Kaplan-Meier method. All the statistical analyses were performed using SPSS software version 19.0 (IBM Japan Ltd., Tokyo, Japan) and two-sided $P$ values of less than 0.05 were considered to indicate statistical significance.

\section{Results}

\section{Clinicopathological background of patients}

The mean age $( \pm \mathrm{SD})$ of the 215 patients was $70.2 \pm 8.4-$ years (range, 45-89; median, 72 years). The mean follow-up period was $46.4 \pm 36.1$ months (range, 1-209; median, 37 months). Of 215 patients, bone metastasis alone, additional lymph nodes metastasis, and other visceral metastasis were seen at initial diagnosis in 106 (49.3\%), 98 (45.6\%), and 15 (7.0\%), respectively. The distribution of Gleason score of biopsy specimen was $<7$ in 15 patients (7.0\%), 7-8 in 81 (37.7\%), 9-10 in 109 (50.7\%), and unknown in 10 (4.6\%). Pretreatment PSA, HGB, ALP, and LDH levels are shown in Table 1. All the patients were received an endocrine therapy as an initial treatment, surgical castration alone in 29 (13.5\%), LH$\mathrm{RH}$ analogue alone in 53 (24.6\%), combined androgen blockade in 131 (60.9\%). Among 188 patients with available data, 91patinets (48.4\%) achieved a PSA nadir less than $1 \mathrm{ng} / \mathrm{ml}$, while 97 patients (51.6\%) did not reach the level after initial endocrine therapies.

\section{Genotyping analysis}

The repeat number of the $C A$ repeat polymorphism ranged from 13 to 20 , and 20 genotypes were observed. The distributions of the genotypes of the $C A$ repeat polymorphisms, rs12423791, rs6220, and rs7136446 were shown in Table 2. Estimated haplotype frequencies of the LD block 3 (rs6220 - rs7136446) were 55.2\% (T-T), 26.7\% $(C-T), 16.8 \%(C-C)$, and $1.3 \%(T-C)$. Thirty-seven patients with heterozygous genotype of both rs6220 and rs7136446 were estimated as having the $T-T$ and $C-C$ haplotypes because estimated haplotype frequency of the $T-C$ haplotype

Table 1 Patients' clinical characteristics

\begin{tabular}{|c|c|c|}
\hline & Mean \pm SD (median) & Range \\
\hline Age (years) & $70.2 \pm 8.4(72)$ & $45-89$ \\
\hline PSA (ng/mL) & $1,029 \pm 1,896(260)$ & $2.4-12,490$ \\
\hline $\mathrm{HGB}(\mathrm{g} / \mathrm{dL})$ & $13.1 \pm 1.9(13.3)$ & $7.4-17.4$ \\
\hline ALP (IU/L) & $615 \pm 908(291)$ & $50-5,870$ \\
\hline LDH (IU/L) & $295 \pm 180(222)$ & $97-1,273$ \\
\hline \multirow[t]{2}{*}{ Follow-up (months) } & $46.4 \pm 36.1(37)$ & $1-209$ \\
\hline & $\mathrm{N}(\%)$ & \\
\hline \multicolumn{3}{|l|}{ Metastases } \\
\hline Bone only & $106(49.3)$ & \\
\hline Lymph nodes & $98(45.6)$ & \\
\hline Other organs & $15(7.0)$ & \\
\hline \multicolumn{3}{|l|}{ Gleason score } \\
\hline$<7$ & $15(7.0)$ & \\
\hline $7-8$ & $81(37.7)$ & \\
\hline $9-10$ & $109(50.7)$ & \\
\hline Unknown & $10(4.6)$ & \\
\hline
\end{tabular}


Table 2 Genotype distributions of four polymorphisms analyzed in this study

\begin{tabular}{cl}
\hline Genotype & $\mathbf{N}(\%)$ \\
\hline CA repeat & \\
$13 / 15$ & $1(0.5)$ \\
$14 / 17$ & $1(0.5)$ \\
$15 / 16$ & $4(1.9)$ \\
$15 / 17$ & $11(5.1)$ \\
$15 / 18$ & $3(1.4)$ \\
$15 / 19$ & $12(5.6)$ \\
$15 / 20$ & $1(0.5)$ \\
$16 / 16$ & $2(0.9)$ \\
$16 / 17$ & $25(11.6)$ \\
$16 / 18$ & $7(3.3)$ \\
$16 / 19$ & $17(7.9)$ \\
$17 / 17$ & $16(7.4)$ \\
$17 / 18$ & $18(8.4)$ \\
$17 / 19$ & $48(22.3)$ \\
$17 / 20$ & $1(0.5)$ \\
$18 / 18$ & $9(4.2)$ \\
$18 / 19$ & $16(7.4)$ \\
$18 / 20$ & $1(0.5)$ \\
$19 / 19$ & $15(0.5)$ \\
$19 / 20$ & $7(7.0)$ \\
rs12423791 & \\
GG & $140(65.1)$ \\
GC & $75(34.9)$ \\
rs6220 & \\
$T T$ & $71(33.0)$ \\
TC & $102(47.5)$ \\
rs & $42(19.5)$ \\
$C C$ & \\
\hline & $146(67.9)$ \\
\hline & $60(27.9)$ \\
\hline & $9(4.2)$ \\
\hline
\end{tabular}

was quite low. Haplotypes in all other patients were uniquely determined.

\section{Survival analysis}

Kaplan-Meier curves demonstrated that patients with 19repeat allele, $C$ allele of rs12423791, or $C$ allele of rs6220 had a significantly worse survival $(P=0.013,0.014$, or 0.014 , respectively). Whereas, rs7136446 was not associated with patients' survival $(P=0.371)$. Patients with at least one $C-T$ haplotype showed significantly worse survival compared with those who had no $C-T$ haplotype $(P=0.0003)$ (Figure 2). When the number of the genetic risk factors (19-repeat allele, $C$ allele of rs12423791, or $C-T$ haplotype) was considered, cancer-specific survival significantly shortened with increased the number of genetic risk factors $(P=0.002)$, and patients with all the genetic risk factors had significantly shorter survival than those with $0-2$ risk factors $(P=0.0003)$ (Figure 3 ).

An univariate Cox proportional hazard regression analysis showed that cancer-specific survival was significantly lower in patients with Gleason score of 9 or higher (HR: $1.759,95 \% \mathrm{CI}: 1.151-2.687, P=0.009$ ), HGB less than $11.5 \mathrm{~g} / \mathrm{dl}$ (HR: 2.251, 95\% CI: 1.261-4.019, $P=0.006$ ), ALP of $350 \mathrm{IU} / \mathrm{ml}$ or higher (HR: $2.836,95 \%$ CI: $1.756-4.578, P=0.00002)$, or $\mathrm{LDH}$ of $500 \mathrm{IU} / \mathrm{ml}$ or higher (HR: 2.638, 95\% CI: 1.442-4.829, $P=0.002$ ) (Table 3). Meanwhile, neither dichotomized age nor PSA was associated with cancer-specific survival. In a multivariate analysis including all the clinicopathological variables and haplotype of the LD block 3 as a representative genetic variable, higher Gleason score (HR: 1.766, 95\% CI: 1.052-2.966, $P=0.031)$, higher ALP (HR: 2.598, 95\% CI: 1.483-4.551, $P=0.0008$ ), and the $C-T$ haplotype (HR: 2.619, 95\% CI: 1.559-4.399, $P=0.0003$ ) were independent factors predicting cancer-specific survival. HGB and LDH showed borderline significance $(P=0.061$ and 0.059 , respectively). In a reduced variable model, higher ALP (HR: 2.819, 95\% CI: $1.695-4.689, P=0.00007$ ) and $C-T$ haplotype (HR: 2.626, 95\% CI: $1.603-4.305, P=0.0001)$ were stronger independent predictors for the survival, followed by HGB (HR: $2.082,95 \%$ CI 1.113-3.897, $P=0.022$ ) and Gleason score (HR: $1.709,95 \%$ CI: 1.054-2.771, $P=0.030$ ) (Table 3).

Because the Gleason score and the pretreatment ALP level were shown to be significant prognostic factors along with the LD Block 3 haplotype by multivariate analysis (Table 3), we performed subgroup analyses according to the dichotomized Gleason score or the dichotomized pretreatment ALP level to compare survivals by presence or absence of $C-T$ haplotype. Among patients with Gleason score of 9-10 $(n=108)$, those with $\mathrm{C}-\mathrm{T}$ haplotype showed significantly worse survival than those having no $C-T$ haplotype $(P=0.0002)$, while there was no significant difference $(P=0.365)$ in patients with Gleason score less than $9(\mathrm{n}=96)$. Regarding ALP, patients with $C-T$ haplotype showed significantly shorter survival than those with no $C-T$ haplotype in either subgroup (ALP higher or lower than $350 \mathrm{IU} / \mathrm{ml})(P=0.010$ or 0.009 , respectively) (Figure 4 ).

\section{Discussion}

The association of the $C A$ repeat polymorphism in the promoter region of the IGF-1 with circulating IGF-1 levels and a risk of breast, prostate, and colorectal cancers have been extensively evaluated [23,29]. In those previous studies, the $C A$ repeat polymorphisms were 

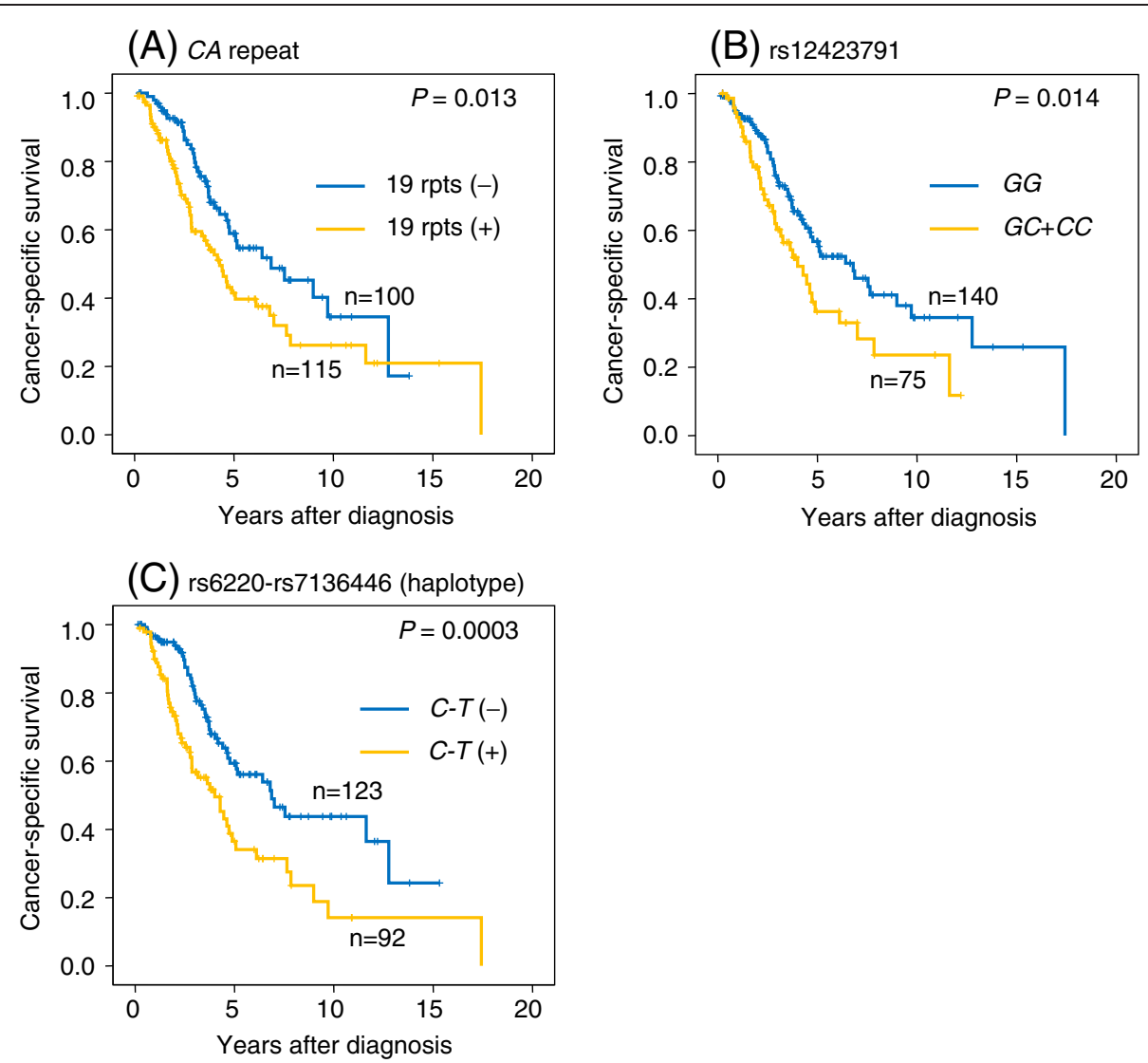

Figure 2 Cancer-specific survival of patients classified based on the risk allele, genotype or haplotype. The survival was significantly worse in patients with 19 CA repeat allele in the LD block1 than those without 19 CA repeat allele $(P=0.013)(\mathbf{A})$. Patients with GC or CC genotype of the rs 12423791 in the LD block 2 had significantly worse survival than those with GG genotype $(P=0.014)(\mathbf{B})$. As regards to the LD block 3 haplotype, patients with C-T haplotype had significantly worse survival than those without C-T haplotype $(P=0.0003)(\mathbf{C})$.
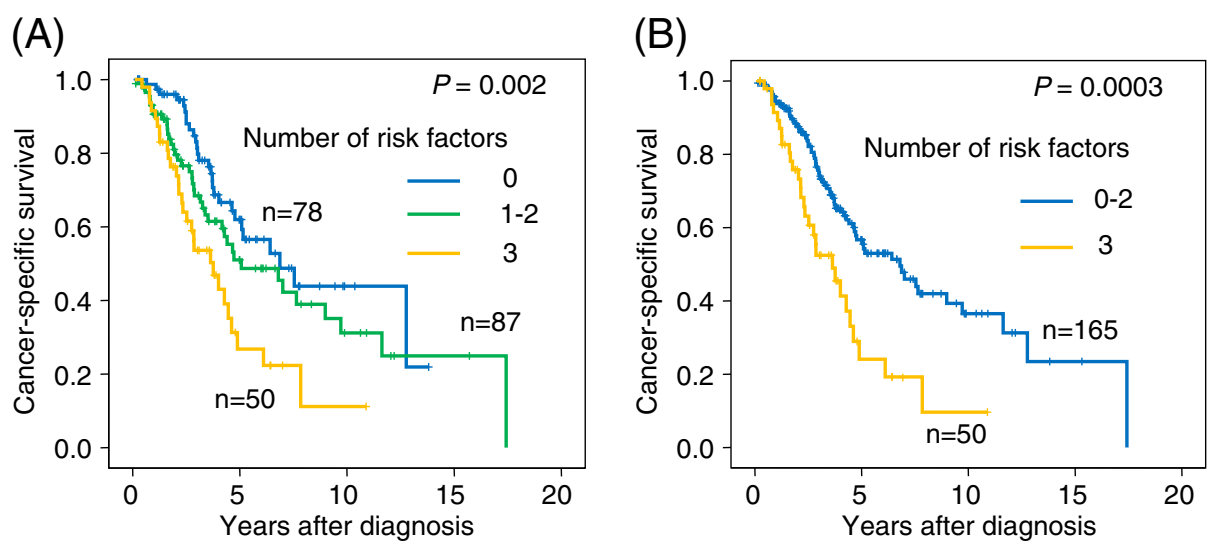

Figure 3 Cancer-specific survival of patients classified based on the sum of genetic risk factors. The genetic risk factors were defined as presence of 19 repeat allele of the CA repeat polymorphism, C allele of the rs 12423791, and C-T haplotype of the LD block 3. Each patient was assigned to one of 3 groups (0, 1-2, or 3 risk factors) (A) or one of 2 groups (0-2 or 3 risk factors) (B). The cancer-specific survivals significantly differed in both of the classification ( $P=0.002$ and 0.0003 ). 
Table 3 Univariate and multivariate analysis of clinicopathological and genetic factors predicting cancer-specific survival

\begin{tabular}{|c|c|c|c|c|}
\hline \multicolumn{5}{|l|}{ Univariate analysis } \\
\hline & Category & $\mathrm{HR}^{1}$ & $95 \% \mathrm{Cl}^{2}$ & $P$ \\
\hline \multicolumn{5}{|c|}{ Clinical and pathological factors } \\
\hline Age (yrs) & $\geq 72$ vs. $<72$ & 1.183 & $0.790-1.772$ & 0.415 \\
\hline Gleason score & $\geq 9$ vs. $<9$ & 1.759 & $1.151-2.687$ & 0.009 \\
\hline PSA (ng/mL) & $\geq 260$ vs. $<260$ & 1.510 & $0.992-2.299$ & 0.054 \\
\hline $\mathrm{HGB}(\mathrm{g} / \mathrm{dL})$ & $<11.5$ vs. $\geq 11.5$ & 2.251 & $1.261-4.019$ & 0.006 \\
\hline ALP (IU/L) & $\geq 350$ vs. $<350$ & 2.836 & $1.756-4.578$ & 0.00002 \\
\hline LDH (IU/L) & $\geq 500$ vs. $<500$ & 2.638 & $1.442-4.829$ & 0.002 \\
\hline \multicolumn{5}{|l|}{ Genetic factors } \\
\hline LD block 1 (CA repeat) & 19 rpts (+) vs. (-) & 1.671 & $1.109-2.518$ & 0.014 \\
\hline LD block 2 (rs12423791) & $G C+C C$ vs. GG & 1.658 & $1.102-2.495$ & 0.015 \\
\hline LD block 3 (haplotype) & $C-T(+)$ vs. $C-T(-)$ & 2.054 & $1.373-3.075$ & 0.0005 \\
\hline \multirow[t]{2}{*}{ Number of risk factors } & 0 vs. $1-2$ vs. 3 & 1.578 & $1.208-2.060$ & 0.0008 \\
\hline & $0-2$ vs. 3 & 2.202 & $1.414-3.430$ & 0.0005 \\
\hline \multicolumn{5}{|l|}{ Multivariate analysis } \\
\hline \multicolumn{5}{|l|}{ Full model } \\
\hline Age (yrs) & $\geq 72$ vs. $<72$ & 0.919 & $0.554-1.526$ & 0.745 \\
\hline Gleason score & $\geq 9$ vs. $<9$ & 1.766 & $1.052-2.966$ & 0.031 \\
\hline PSA (ng/mL) & $\geq 265$ vs. $<265$ & 0.932 & $0.496-1.749$ & 0.826 \\
\hline $\mathrm{HGB}(\mathrm{g} / \mathrm{dL})$ & $<11.5$ vs. $\geq 11.5$ & 2.012 & $0.968-4.180$ & 0.061 \\
\hline ALP (IU/L) & $\geq 350$ vs. $<350$ & 2.598 & $1.483-4.551$ & 0.0008 \\
\hline LDH (IU/L) & $\geq 500$ vs. $<500$ & 1.836 & $0.977-3.448$ & 0.059 \\
\hline LD Block 3 (haplotype) & $C-T(+)$ vs. $C-T(-)$ & 2.619 & $1.559-4.399$ & 0.0003 \\
\hline \multicolumn{5}{|l|}{ Reduced model } \\
\hline Gleason score & $\geq 9$ vs. $<9$ & 1.709 & $1.054-2.771$ & 0.030 \\
\hline $\mathrm{HGB}(\mathrm{g} / \mathrm{dL})$ & $<11.5$ vs. $\geq 11.5$ & 2.082 & $1.113-3.897$ & 0.022 \\
\hline ALP (IU/L) & $\geq 350$ vs. $<350$ & 2.819 & $1.695-4.689$ & 0.00007 \\
\hline LD Block 3 (haplotype) & $C-T(+)$ vs. $C-T(-)$ & 2.626 & $1.603-4.305$ & 0.0001 \\
\hline
\end{tabular}

${ }^{1} \mathrm{HR}$, hazard ratio; ${ }^{2} 95 \% \mathrm{Cl}, 95 \%$ confidence interval.

generally categorized as having a 19-repeat allele or not having the allele. To date, however, the results were inconsistent in terms of whether 19-repeat allele increases IGF-1 levels or cancer risks. A recent large-scale study of 6,400 healthy subjects indicated that other polymorphisms downstream of the $C A$ repeat polymorphism may affect IGF-1 circulation levels [30]. In prostate cancer patients, Johansson et al. demonstrated that heterozygous haplotype of $T-C-C$ (rs6220-rs7136446-rs2033178 [GenBank]) in the $3^{\prime}$ region of the IGF-1, which was a risk haplotype of prostate cancer risk in their previous study, was significantly associated with higher circulating levels of IGF-1 [27]. In the study, however, another cohort did not show the significant difference in circulating IGF-1 levels and rather patients with rs6220 CC genotype showed significantly higher circulating IGF-1 level in a separate SNP analysis of each SNP [27]. Other study also showed significantly increased circulating IGF-1 levels in females with rs6220 CC genotype [31]. Since all the patients in our series had the $C C$ genotype at rs2033178 (data not shown), the T-C-C haplotype is referred to as the $T-C$ haplotype in our study. Although the $T-C(T-C-C)$ haplotype was not separately analyzed in a survival analysis due to the rare haplotype with only $1.3 \%$, our result showed that patients with the $C-T$ haplotype had significantly worse survival and appeared to be in line with previous studies investigating the association between circulating IGF-1 levels and the IGF-1 polymorphisms.

Multiple interpretations are possible regarding the role of the polymorphisms in altering the circulating IGF-1 levels. A previous study demonstrated in other genes 

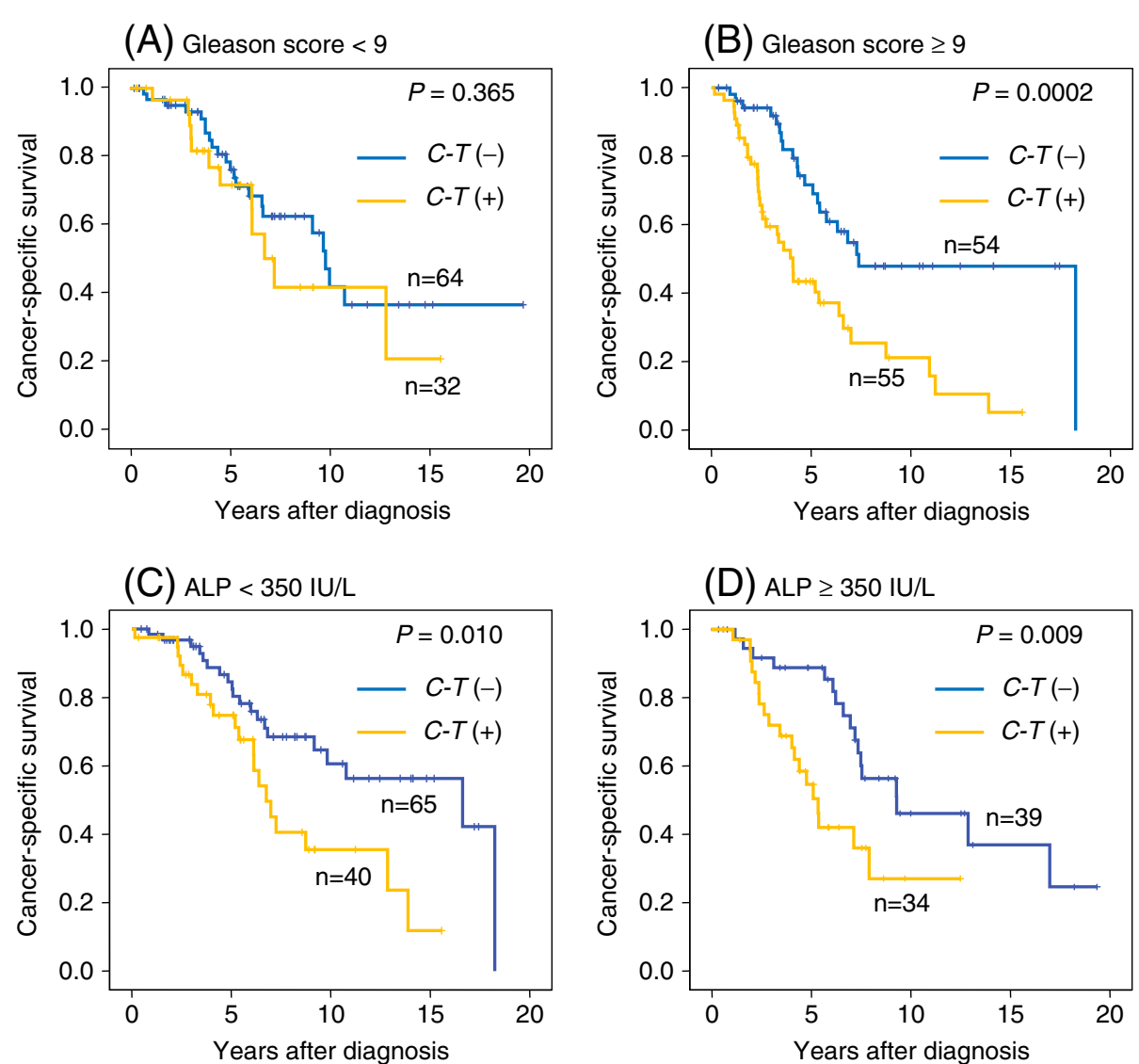

Figure 4 Cancer-specific survival of patients classified based on haplotype in the LD block 3 in subgroups dichotomized by Gleason score or pretreatment ALP level. Patients with C-T haplotype showed significantly worse survival than those having no C-T haplotype $(P=0.0002)$ in patients with Gleason score of 9-10 (A), while there was no significant difference $(P=0.365)$ in patients with Gleason score less than 9 (B). In a subgroup analysis by pretreatment ALP level, patients with C-T haplotype showed significantly shorter survival than those with no C-T haplotype in either subgroup of patients with lower ( $<350 \mathrm{IU} / \mathrm{L})$ or higher ( $\geq 350 \mathrm{IU} / \mathrm{L}) \mathrm{ALP}(P=0.010$ or 0.009 , respectively) (C and $\mathbf{D})$.

that the $C A$ repeat in the promoter region acted as a negative control element [32], suggesting a possibility that a $C A$ repeat length directly affects the transcriptional activity of the IGF-1. This hypothesis is partially supported by a study conducted by Missmer et al. [33]. They showed a trend of decreasing IGF-1 level with increasing the $C A$ repeat length genotype, although this was not statistically significant [33]. Another explanation is that $C A$ repeats do not directly affect the transcriptional activity but other SNPs being in linkage disequilibrium exert functional effect on a transcriptional activity. Recent studies demonstrated that SNPs or haplotypes in other regions in the IGF-1, especially downstream of the $C A$ repeats, were associated with circulating IGF-1 levels or cancer susceptibility $[24,30]$. Chen et al. reported a possible association of a haplotype combined of SNPs and the $C A$ repeat length with circulation IGF-1 levels. In the study, the combined haplotype was correlated with circulating IGF-1 levels and neither SNPs nor the $C A$ repeat alone was associated with the
IGF-1 levels [34]. Nevertheless, in vitro studies are needed to determine the functional implication of those genetic polymorphisms on the alteration of IGF-1 expression.

Several mechanisms of IGF-1 affecting the prognosis of metastatic prostate cancer are envisioned. First, IGF-1 is known to act as an important growth factor regulating proliferation and apoptosis of cancer cells and has a role in an acquisition of resistance to endocrine therapies [35-37]. Secondary, IGF-1, which is also produced by bone cells, down-regulates osteoprotegerin (OPG) and up-regulated receptor activator of NF- $\mathrm{kB}$ ligand (RANKL) [38]. Results of the present study suggest that the polymorphisms are associated with an aggressive phenotype and resistance to endocrine therapy and facilitate the progression of prostate cancer cells especially in bone metastasis.

The present study has several limitations. First, the present study has a possible bias of patient selection, which is a drawback of retrospective study design. Although the majority of the patients are incident cases, some patients who had rapid progression and very short- 
term survival may have not been enrolled into the study. Second, treatment strategy was not regulated in this retrospective study. Because of the long recruiting period, various treatments except for endocrine therapies including docetaxel were administered only in recent cases. A prospective study with a large cohort is mandatory to validate the results. Thirdly, we examined only 4 polymorphism loci and other SNPs may have a stronger association with the survival than those evaluated in the present study. A study using precise SNP panel may lead to identify SNPs truly responsible for the survival and the function of the SNPs should be supported by biological investigations.

\section{Conclusions}

Polymorphisms of the $I G F-1$, especially $C-T$ haplotype in the LD block 3 were associated with worse survival of prostate cancer patients with bone metastasis at initial diagnosis. The genomic variations in the IGF-1 combined with conventional clinicopathological prognostic markers, along with conventional clinical markers, appeared to be useful for predicting the outcome of metastatic prostate cancer.

\begin{abstract}
Abbreviations
EOD: Extent of disease; ALP: Alkaline phosphate; HGB: Hemoglobin;

PSA: Prostate specific antigen; IGF-1: Insulin-like growth factor-1;

CYP19: Cytochrome P450 aromatase; SNP: Single nucleotide polymorphism; LH-RH: Luteinizing hormone-releasing hormone; LDH: Lactate dehydrogenase; PCR: Polymerase chain reaction; RFLP: Restriction fragment length polymorphism; RANKL: Receptor activator of NF-KB ligand.
\end{abstract}

\section{Competing interests}

The authors declare that they have no competing interests.

\section{Authors' contributions}

NT and TH were involved in the conception and design of the study. SN, TI, and $\mathrm{MH}$ performed laboratory work. MS, KN, SS, SH, and $\mathrm{OO}$ were involved in the provision of study material and patients' clinical data. NT and TH drafted the manuscript. SS, CO, YA, OO supported the manuscript writing. All authors have read and approved the final manuscript.

\section{Acknowledgements}

The authors are grateful to Ms. Yoko Mitobe (Department of Urology, Akita University Graduate School of Medicine) for her excellent technical assistance. This study was supported by grants from Grants-in-Aid for Scientific Research from the Ministry of Education, Culture, Sports, Science and Technology of Japan (19591833, 21592029, 22390302, 24592373).

\footnotetext{
Author details

'Department of Urology, Akita University Graduate School of Medicine, 1-1-1 Hondo, Akita 010-8543, Japan. ²Department of Urology, Hirosaki University Graduate School of Medicine, 5 Zaifu-cho, Hirosaki, Aomori 036-8562, Japan. ${ }^{3}$ Division of Urology, Department of Organ-oriented Medicine, University of the Ryukyu, 207 Uehara, Nishihara, Okinawa 903-0215, Japan. ${ }^{4}$ Department of Urology, Tohoku University Graduate School of Medicine, 2-1 Seiryo-machi, Aoba-ku, Sendai 980-8575, Japan. ${ }^{5}$ Department of Urology, Graduate School of Medicine, Kyoto University, 54 Syogoin-kawaramachi, Sakyo-ku, Kyoto 606-8507, Japan.
}

Received: 27 November 2012 Accepted: 18 March 2013

Published: 25 March 2013

\section{References}

1. Resnick MI, Grayhack JT: Treatment of stage IV carcinoma of the prostate. Urol Clin North Am 1975, 2(1):141-161

2. de Bono JS, Logothetis CJ, Molina A, Fizazi K, North S, Chu L, Chi KN, Jones RJ, Goodman OB Jr, Saad F, et al: Abiraterone and increased survival in metastatic prostate cancer. N Engl J Med 2011, 364(21):1995-2005.

3. Scher HI, Beer TM, Higano CS, Anand A, Taplin ME, Efstathiou E, Rathkopf D, Shelkey J, Yu EY, Alumkal J, et al: Antitumour activity of MDV3100 in castration-resistant prostate cancer: a phase 1-2 study. Lancet 2010, 375(9724):1437-1446.

4. de Bono JS, Oudard S, Ozguroglu M, Hansen S, Machiels JP, Kocak I, Gravis G, Bodrogi I, Mackenzie MJ, Shen L, et al: Prednisone plus cabazitaxel or mitoxantrone for metastatic castration-resistant prostate cancer progressing after docetaxel treatment: a randomised open-label trial. Lancet 2010, 376(9747):1147-1154.

5. Soloway MS, Hardeman SW, Hickey D, Raymond J, Todd B, Soloway S, Moinuddin M: Stratification of patients with metastatic prostate cancer based on extent of disease on initial bone scan. Cancer 1988, 61(1):195-202.

6. Merrick MV, Ding CL, Chisholm GD, Elton RA: Prognostic significance of alkaline and acid phosphatase and skeletal scintigraphy in carcinoma of the prostate. Br J Urol 1985, 57(6):715-720.

7. Fossa SD, Paus E, Lindegaard M, Newling DW: Prostate-specific antigen and other prognostic factors in patients with hormone-resistant prostatic cancer undergoing experimental treatment. Br J Urol 1992, 69(2):175-179.

8. Cooper EH, Armitage TG, Robinson MR, Newling DW, Richards BR, Smith PH, Denis $L$, Sylvester R: Prostatic specific antigen and the prediction of prognosis in metastatic prostatic cancer. Cancer 1990, 66(5 Suppl):1025-1028.

9. Yang $M$, Xie W, Mostaghel E, Nakabayashi M, Werner L, Sun T, Pomerantz M, Freedman M, Ross R, Regan M, et al: SLCO2B1 and SLCO1B3 may determine time to progression for patients receiving androgen deprivation therapy for prostate cancer. J Clinical Oncol: Official Journal of The American Society of Clinical Oncology 2011, 29(18):2565-2573.

10. Tsuchiya N, Wang L, Suzuki H, Segawa T, Fukuda H, Narita S, Shimbo M, Kamoto T, Mitsumori K, Ichikawa T, et al: Impact of IGF-I and CYP19 gene polymorphisms on the survival of patients with metastatic prostate cancer. J Clin Oncol 2006, 24(13):1982-1989.

11. Penney KL, Pyne S, Schumacher FR, Sinnott JA, Mucci LA, Kraft PL, Ma J, Oh WK, Kurth T, Kantoff PW, et al: Genome-wide association study of prostate cancer mortality. Cancer Epidemiol Biomarkers Prev 2010, 19(11):2869-2876.

12. Lin DW, FitzGerald LM, Fu R, Kwon EM, Zheng SL, Kolb S, Wiklund F, Stattin $P$, Isaacs WB, XU J, et al: Genetic variants in the LEPR, CRY1, RNASEL, IL4, and ARVCF genes are prognostic markers of prostate cancer-specific mortality. Cancer Epidemiol Biomarkers Prev 2011, 20(9):1928-1936.

13. Wu JD, Odman A, Higgins LM, Haugk K, Vessella R, Ludwig DL, Plymate SR: In vivo effects of the human type I insulin-like growth factor receptor antibody A12 on androgen-dependent and androgen-independent xenograft human prostate tumors. Clinical Cancer Res: an Official Journal of the American Association for Cancer Research 2005, 11(8):3065-3074.

14. Montagnani Marelli M, Moretti RM, Procacci P, Motta M, Limonta P: Insulinlike growth factor-I promotes migration in human androgenindependent prostate cancer cells via the alphavbeta3 integrin and PI3K/Akt signaling. Int J Oncol 2006, 28(3):723-730.

15. Rowlands MA, Holly JM, Gunnell D, Donovan J, Lane JA, Hamdy F, Neal DE, Oliver S, Smith GD, Martin RM: Circulating insulin-like growth factors and IGF-binding proteins in PSA-detected prostate cancer: the large casecontrol study ProtecT. Cancer Res 2012, 72(2):503-515.

16. Harrela M, Koistinen H, Kaprio J, Lehtovirta M, Tuomilehto J, Eriksson J, Toivanen L, Koskenvuo M, Leinonen P, Koistinen R, et al: Genetic and environmental components of interindividual variation in circulating levels of IGF-I, IGF-II, IGFBP-1, and IGFBP-3. J Clin Invest 1996, 98(11):2612-2615.

17. Key TJ, Appleby PN, Reeves GK, Roddam AW: Insulin-like growth factor 1 (IGF1), IGF binding protein 3 (IGFBP3), and breast cancer risk: pooled individual data analysis of 17 prospective studies. Lancet Oncol 2010, 11(6):530-542.

18. Rinaldi S, Cleveland R, Norat T, Biessy C, Rohrmann S, Linseisen J, Boeing $\mathrm{H}_{\text {, }}$ Pischon T, Panico S, Agnoli C, et al: Serum levels of IGF-I, IGFBP-3 and colorectal cancer risk: results from the EPIC cohort, plus a meta-analysis of prospective studies. International Journal of Cancer Journal international du cancer 2010, 126(7):1702-1715

19. Tsuchiya N, Wang L, Horikawa Y, Inoue T, Kakinuma H, Matsuura S, Sato K, Ogawa O, Kato T, Habuchi T: CA repeat polymorphism in the insulin-like growth factor-I gene is associated with increased risk of prostate cancer and benign prostatic hyperplasia. Int J Oncol 2005, 26(1):225-231. 
20. Chan JM, Stampfer MJ, Ma J, Gann P, Gaziano JM, Pollak M, Giovannucci E: Insulin-like growth factor-I (IGF-I) and IGF binding protein-3 as predictors of advanced-stage prostate cancer. J Natl Cancer Inst 2002, 94(14):1099-1106.

21. Jernstrom H, Chu W, Vesprini D, Tao Y, Majeed N, Deal C, Pollak M, Narod SA: Genetic factors related to racial variation in plasma levels of insulinlike growth factor-1: implications for premenopausal breast cancer risk. Mol Genet Metab 2001, 72(2):144-154.

22. Rosen CI, Kurland ES, Vereault D, Adler RA, Rackoff PJ, Craig WY, Witte S, Rogers J, Bilezikian JP: Association between serum insulin growth factor-I (IGF-I) and a simple sequence repeat in IGF-I gene: implications for genetic studies of bone mineral density. J Clin Endocrinol Metab 1998, 83(7):2286-2290

23. Chen X, Guan J, Song Y, Chen P, Zheng H, Tang C, Wu Q: IGF-I (CA) repeat polymorphisms and risk of cancer: a meta-analysis. J Hum Genet 2008, 53(3):227-238

24. Cheng I, Stram DO, Penney KL, Pike M, Le Marchand L, Kolonel LN, Hirschhorn J, Altshuler D, Henderson BE, Freedman ML: Common genetic variation in IGF1 and prostate cancer risk in the Multiethnic Cohort. J Natl Cancer Inst 2006, 98(2):123-134.

25. Johansson M, McKay JD, Stattin P, Canzian F, Boillot C, Wiklund F, Adami $\mathrm{HO}$, Balter $\mathrm{K}$, Gronberg $\mathrm{H}$, Kaaks R: Comprehensive evaluation of genetic variation in the IGF1 gene and risk of prostate cancer. International Journal of Cancer Journal International du cancer 2007, 120(3):539-542.

26. Verheus M, McKay JD, Kaaks R, Canzian F, Biessy C, Johansson M, Grobbee DE, Peeters $\mathrm{PH}$, van Gils $\mathrm{CH}$ : Common genetic variation in the IGF-1 gene, serum IGF-I levels and breast density. Breast Cancer Res Treat 2008, 112(1):109-122.

27. Johansson M, McKay JD, Wiklund F, Rinaldi S, Verheus M, van Gils CH, Hallmans G, Balter K, Adami HO, Gronberg H, et al: Implications for prostate cancer of insulin-like growth factor-I (IGF-I) genetic variation and circulating IGF-I levels. J Clin Endocrinol Metab 2007, 92(12):4820-4826.

28. Consortium: $\mathrm{IH}$ : A haplotype map of the human genome. Nature 2005, 437(7063):1299-1320.

29. Fletcher O, Gibson L, Johnson N, Altmann DR, Holly JM, Ashworth A, Peto J, Silva Idos S: Polymorphisms and circulating levels in the insulin-like growth factor system and risk of breast cancer: a systematic review. Cancer epidemiology, biomarkers \& prevention: a publication of the American Association for Cancer Research, cosponsored by the American Society of Preventive Oncology 2005, 14(1):2-19.

30. Patel AV, Cheng I, Canzian F, Le Marchand L, Thun MJ, Berg CD, Buring J, Calle EE, Chanock S, Clavel-Chapelon F, et al: IGF-1, IGFBP-1, and IGFBP-3 polymorphisms predict circulating IGF levels but not breast cancer risk: findings from the Breast and Prostate Cancer Cohort Consortium (BPC3). PLoS One 2008, 3(7):e2578.

31. Al-Zahrani A, Sandhu MS, Luben RN, Thompson D, Baynes C, Pooley KA, Luccarini C, Munday H, Perkins B, Smith P, et al: IGF1 and IGFBP3 tagging polymorphisms are associated with circulating levels of IGF1, IGFBP3 and risk of breast cancer. Hum Mol Genet 2006, 15(1):1-10

32. Tae HJ, Luo X, Kim KH: Roles of CCAAT/enhancer-binding protein and its binding site on repression and derepression of acetyl-CoA carboxylase gene. J Biol Chem 1994, 269(14):10475-10484.

33. Missmer SA, Haiman CA, Hunter DJ, Willett WC, Colditz GA, Speizer FE, Pollak MN, Hankinson SE: A sequence repeat in the insulin-like growth factor-1 gene and risk of breast cancer. International journal of cancer Journal international du cancer 2002, 100(3):332-336.

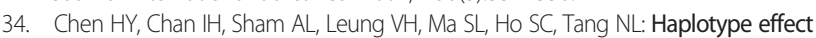
in the IGF1 promoter accounts for the association between microsatellite and serum IGF1 concentration. Clin Endocrinol 2011, 74(4):520-527.

35. Qu BH, Karas M, Koval A, LeRoith D: Insulin receptor substrate-4 enhances insulin-like growth factor-l-induced cell proliferation. J Biol Chem 1999, 274(44):31179-31184.

36. Parrizas M, Saltiel AR, LeRoith D: Insulin-like growth factor 1 inhibits apoptosis using the phosphatidylinositol 3'-kinase and mitogenactivated protein kinase pathways. J Biol Chem 1997, 272(1):154-161.
37. Culig Z, Hobisch A, Cronauer MV, Radmayr C, Trapman J, Hittmair A, Bartsch $\mathrm{G}$, Klocker $\mathrm{H}$ : Androgen receptor activation in prostatic tumor cell lines by insulin-like growth factor-l, keratinocyte growth factor, and epidermal growth factor. Cancer Res 1994, 54(20):5474-5478.

38. Rubin J, Ackert-Bicknell CL, Zhu L, Fan X, Murphy TC, Nanes MS, Marcus R, Holloway L, Beamer WG, Rosen CJ: IGF-I regulates osteoprotegerin (OPG) and receptor activator of nuclear factor-kappaB ligand in vitro and OPG in vivo. J Clin Endocrinol Metab 2002, 87(9):4273-4279.

doi:10.1186/1471-2407-13-150

Cite this article as: Tsuchiya et al:: Insulin-like growth factor-1 genotypes and haplotypes influence the survival of prostate cancer patients with bone metastasis at initial diagnosis. BMC Cancer 2013 13:150.

\section{Submit your next manuscript to BioMed Central and take full advantage of:}

- Convenient online submission

- Thorough peer review

- No space constraints or color figure charges

- Immediate publication on acceptance

- Inclusion in PubMed, CAS, Scopus and Google Scholar

- Research which is freely available for redistribution

Submit your manuscript at www.biomedcentral.com/submit
C) Biomed Central 